\author{
Zbigniew KOWAL ${ }^{1}$ \\ Rafał PIOTROWSKI ${ }^{2}$
}

\title{
ENERGOAKTYWNE SEGMENTY HAL PRZEKRYTE REGULARNĄ STRUKTURĄ KOSZOWA
}

\begin{abstract}
W pracy pokazano koncepcję hali przekrytej regularną strukturą koszową, charakteryzującą się znaczącą powierzchnią przekrycia, nadającą się do zagospodarowania absorberami, do pozyskiwania energii cieplnej oraz elektrycznej z promieniowania słonecznego. Dodatkowym atutem przekrycia koszowego jest ułatwione samooczyszczanie powierzchni pokrycia ze śniegu zwiększające nasłonecznienie absorberów w okresie zimowym. Rozmieszczenie i ilość absorberów zależą od bilansu energetycznego hali. W hali wydzielono energoaktywne segmenty dylatacyjne w celu zredukowania wpływów termicznych na konstrukcję. Podzielono halę na segmenty konwencjonalne oraz segmenty energoaktywne (SE). Segmenty energoaktywne zbudowano z geometrycznie niezmiennych segmentów montażowych, umożliwiających sprawny i bezpieczny montaż. Szerokość minimalnego segmentu energoaktywnego dobrano $\mathrm{z}$ warunku minimum wpływów termicznych przy zachowaniu niezawodności o wskaźniku $t_{2} \geq 3,8$ [9]. W przypadku konieczności dalszego zmniejszenia szerokości segmentów energoaktywnych należy dostroić niezawodność do zaleceń normy [9]. Wydzielone minimalne segmenty energoaktywne przekryte strukturą regularną charakteryzują się znaczącą redukcją wpływu temperatury na wytężenie prętów poprzez zastosowanie przegubu w kluczu. Zastosowano asekurację niesymetrycznych przemieszczeń za pomocą zdwojonych przekrojów prętów skrajnych pasów górnych. Zastosowano równoległe sprzężenia elementów sprawczych w kinematycznie dopuszczalnych mechanizmach zniszczenia (KDMZ) segmentów zwiększając niezawodność powyżej zalecanej w klasie RC2 [9]. W konstrukcjach hal przekrytych strukturami udało się korzystnie wydzielić energoaktywne segmenty dylatacyjne, w których dostateczna liczba elementów sprawczych daje się sprzęgać w KDMZ zwiększając nośność i niezawodność konstrukcji powyżej oczekiwań [9] normowych.
\end{abstract}

Słowa kluczowe: energoaktywne segmenty hal, struktury metalowe, przekrycia koszowe, niezawodność konstrukcji

\footnotetext{
${ }^{1}$ Autor do korespondencji: Rafał Piotrowski, Politechnika Świętokrzyska, Wydział Budownictwa i Architektury, al. Tysiąclecia Państwa Polskiego 7, 25-314 Kielce, (41) 3424 802, rafalp@tu.kielce.pl

${ }^{2}$ Zbigniew Kowal; Politechnika Świętokrzyska, Wydział Budownictwa i Architektury, al. Tysiąclecia Państwa Polskiego 7, 25-314 Kielce, (41) 3424 576, zbigko@tu.kielce.pl
} 


\section{Wprowadzenie}

W pracy [8] pokazano pilaste energoaktywne przekrycie łukowe w postaci energoaktywnych dźwigarów trójpasowych. Podano koncepcję konstrukcji przekrycia oraz technologię pozyskiwania, transportu i magazynowania energii cieplnej otrzymywanej z promieniowania słonecznego.

W niniejszej pracy przedstawiono koncepcję konstrukcji energoaktywnych segmentów dylatacyjnych [4,5,6,7], przekrytych regularną trójprzegubową strukturą koszową. Przewidziano również alternatywne rozwiązanie dwuprzegubowe w drodze zablokowania przegubu w kluczu. Takie rozwiązanie umożliwia również wariantowanie montażu. Zaletą trójprzegubowego przekrycia cylindrycznego jest redukcja wpływów termicznych działających poprzecznie do osi hali bez naruszania idei minimalnego segmentu energoaktywnego zawierającego dostateczną liczbę elementów równolegle połączonych z punktu widzenia niezawodności nie wymagającego dostrajania nośności elementów do niezawodności zalecanej w normie [9].

Przyjęte rozwiązanie spełnia postulat najkrótszej drogi sprowadzenia obciążeń do fundamentów. Zasadnicze obciążenie ściskające przenoszone jest przez łukowe pasy górne oznaczone grubą linią (PG) (rys. 1), które dochodzą do węzłów podporowych (fundamentów). Pozostałe elementy konstrukcji (tzn. pasy dolne (PD) oraz skratowanie (SK)) przenoszą resztkowe siły poprzeczne i zginanie. W przypadku zastosowania przegubu w kluczu w przyjętym schemacie konstrukcji występuje zasadnicza redukcja sił termicznych w konstrukcji hali.

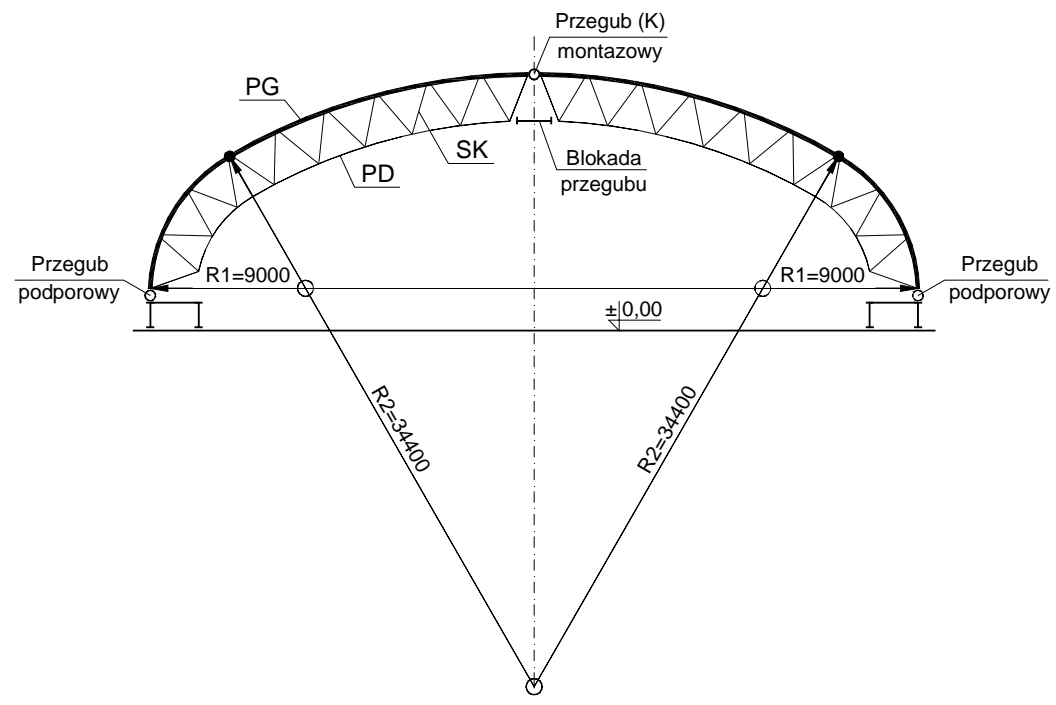

Rys. 1. Energoaktywny segment hali przekrytej regularną strukturą koszową

Fig. 1. Energy-active segment of steel hall covered by regular arc structure 
W koncepcji podziału hali na segmenty dylatacyjne wzięto pod uwagę swobodne wydłużenie termiczne $\Delta_{T}$ po szerokości $L_{d}$ energoaktywnego segmentu dylatacyjnego hali, spowodowane temperaturą. Zastosowano automatyczne włączanie transportu ogrzanego powietrza do odbiorników lub magazynów EC za pomocą wentylatorów ssąco - tłoczących przy osiągnięciu umownej temperatury nagrzewanego powietrza np. powyżej $+20^{\circ} \mathrm{C}$.

Geometrycznie niezmienną konstrukcję energoaktywnego segmentu dylatacyjnego hali złożono z geometrycznie niezmiennych segmentów montażowych umożliwiających swobodny montaż oraz optymalizację czasu i kosztów montażu konstrukcji hali [4].

\section{Koncepcja energoaktywnych segmentów hal przekrytych regularną strukturą koszową}

Na rysunku 2a pokazano przykładową koncepcję konstrukcji hali przekrytej regularną strukturą koszową, o górnych oczkach kwadratowych $(a=3 \mathrm{~m})$ oraz rozpiętości $L=42 \mathrm{~m}$. Geometrię przekrycia (promienie $R_{1}=9 \mathrm{~m}$ oraz $R_{2}=34,4 \mathrm{~m}$ ) dobrano tak, aby wysokość użytkowa hali (od posadzki do pasa dolnego) wynosiła $\mathrm{H}=12 \mathrm{~m}$ (rys. 2a). Zwiększenie wysokości lub rozpiętości najlepiej uzyskać w drodze symetrycznego dołożenia dwóch oczek. Całkowitą długość hali (rys. 3) $L=78 \mathrm{~m}+2 b$ (gdzie: b - odstęp między segmentami), podzielono na typowe $\left(L_{d}=10 a=30 \mathrm{~m}\right)$ oraz energoaktywne $\left(L_{d}=6 a=18 \mathrm{~m}\right)$ segmenty dylatacyjne. Liczba oraz rozmieszczenie segmentów energoaktywnych zależy od bilansu zagospodarowania energetycznego hali. Na rysunku 4 pokazano wariantowe rozmieszczenie segmentów konwencjonalnych oraz energoaktywnych.

Na rysunku $3 b$ pokazano przykład minimalnego energoaktywnego segmentu dylatacyjnego $\left(L_{d}=3 \times 2 a=6 a=18 \mathrm{~m}\right)$ złożonego z 3 geometrycznie niezmiennych segmentów montażowych szerokości 2 oczek $(2 a=6 \mathrm{~m})$ każdy. Przedstawiony segment spełnia warunek niezawodności o wskaźniku $t_{2} \geq 3,8$. W przypadku zmniejszenia szerokości segmentu energoaktywnego np. do dwóch oczek należy oszacować współczynnik dostrojenia niezawodności do zaleceń normy [9] na podstawie pracy [2].

Pomiędzy segmentami dylatacyjnymi zastosowano odstęp $b<a$, dający odciążenie skrajnych pasów górnych i dolnych struktury (rys. 2b,3). Zmniejszenie odstępu $(\mathrm{b}<\mathrm{a})$ asekuruje symetryczne przemieszczenie węzłów wirtualnych kinematycznie dopuszczalnych mechanizmów zniszczenia (KDMZ) w stanie granicznym pasów. Asekurację można zastosować również w skrajnych pasmach segmentów w postaci niezredukowanych przekroi prętów (rys. 2b oraz rys 5 ). 


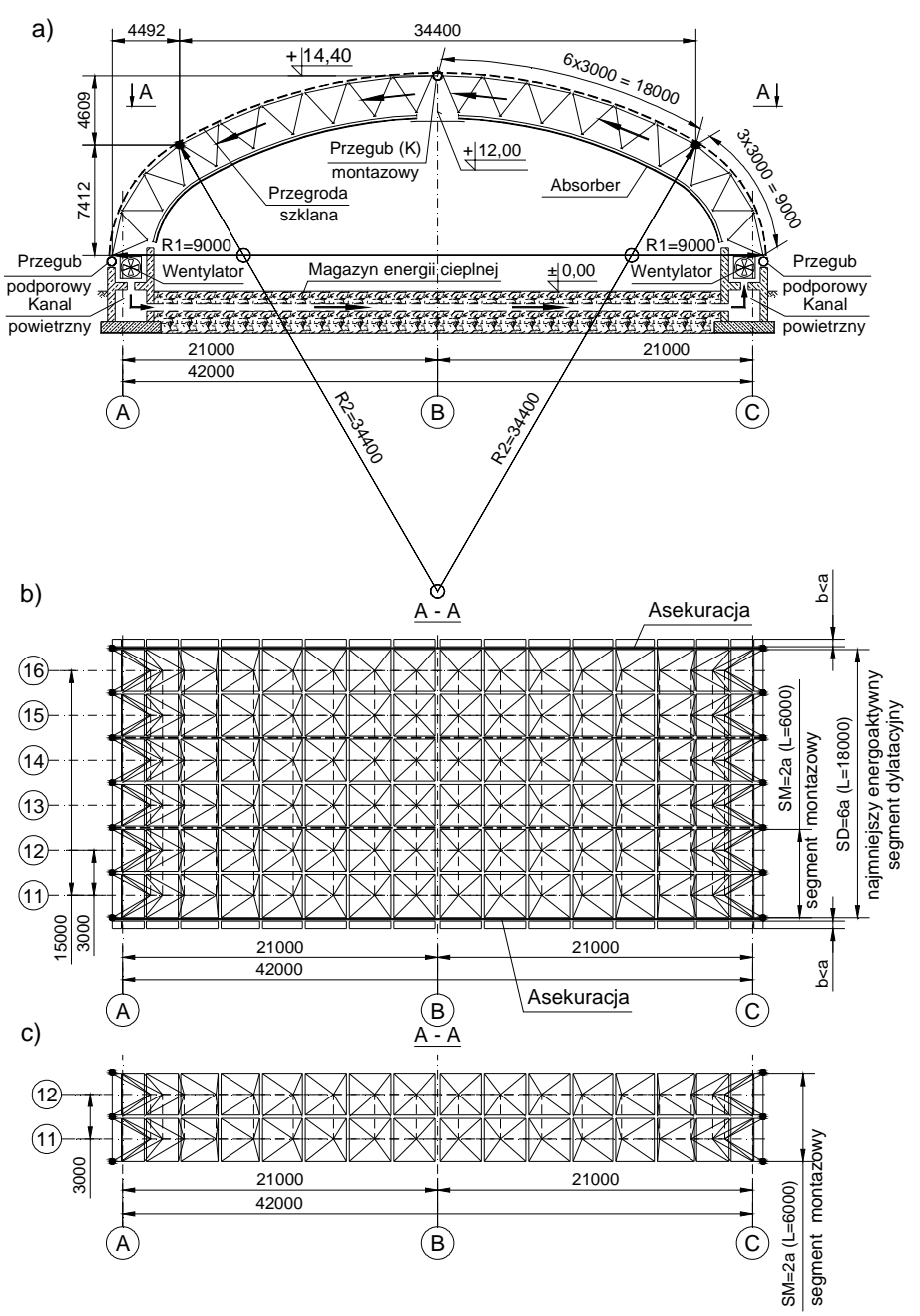

Rys. 2. Minimalny segment dylatacyjny hali przekrytej regularną strukturą koszową: a) przekrój poprzeczny hali, b) podział segmentu dylatacyjnego na segmenty montażowe, c) segment montażowy

Fig. 2. Minimal expansion segment of steel hall covered by regular arc structure: a) cross-section, b) division expansion segment into assemblies segment, c) assembly segment

Segmenty montażowe składane są na poziomie terenu (począwszy od łożysk) z elementów wysyłkowych postaci odwróconych piramid prętowych, w piramidowo bocznym systemie montażowym. Po wstępnym montażu możemy zablokować przeguby w kluczu. Kolejne segmenty montażowe montowane są stycznie do wcześniej osadzonych. Sąsiadujące pasy górne elementów montażowych łączone są śrubami. Sąsiadujące węzły dolne segmentów montażowych łączone są prętami dolnymi również na śruby. 


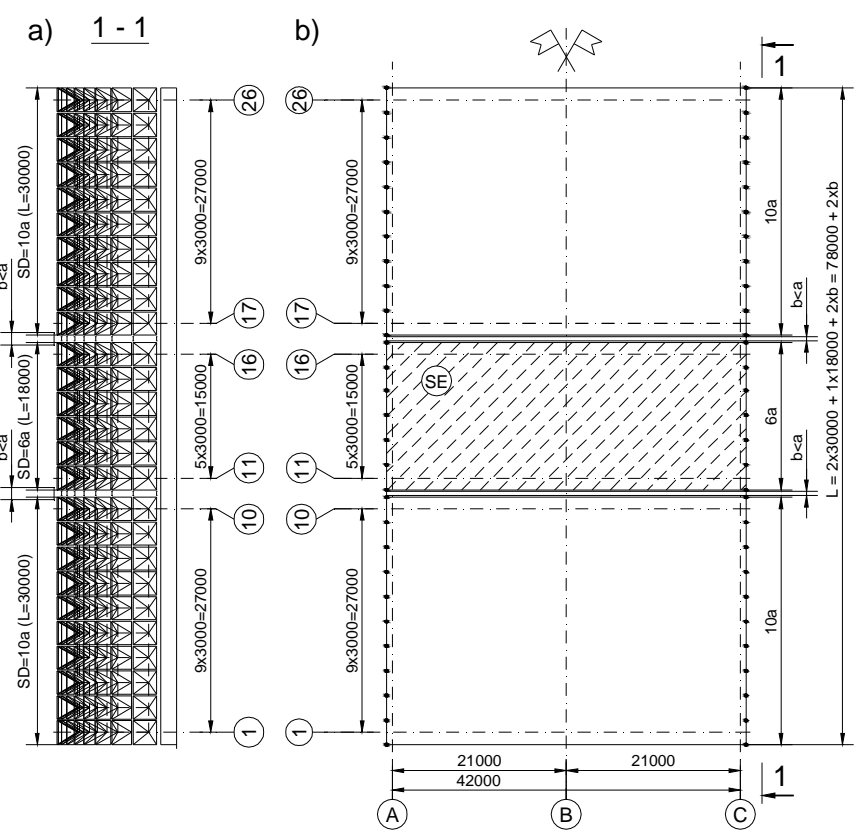

Rys. 3. Przykład wydzielenia segmentów energoaktywnych: a) widok z boku, b) wydzielenie konwencjonalnych oraz energoaktywnych (SE) segmentów

Fig. 3. Example of separate energy-active segments: a) side view, b) separate traditional and energy-active (SE) segments
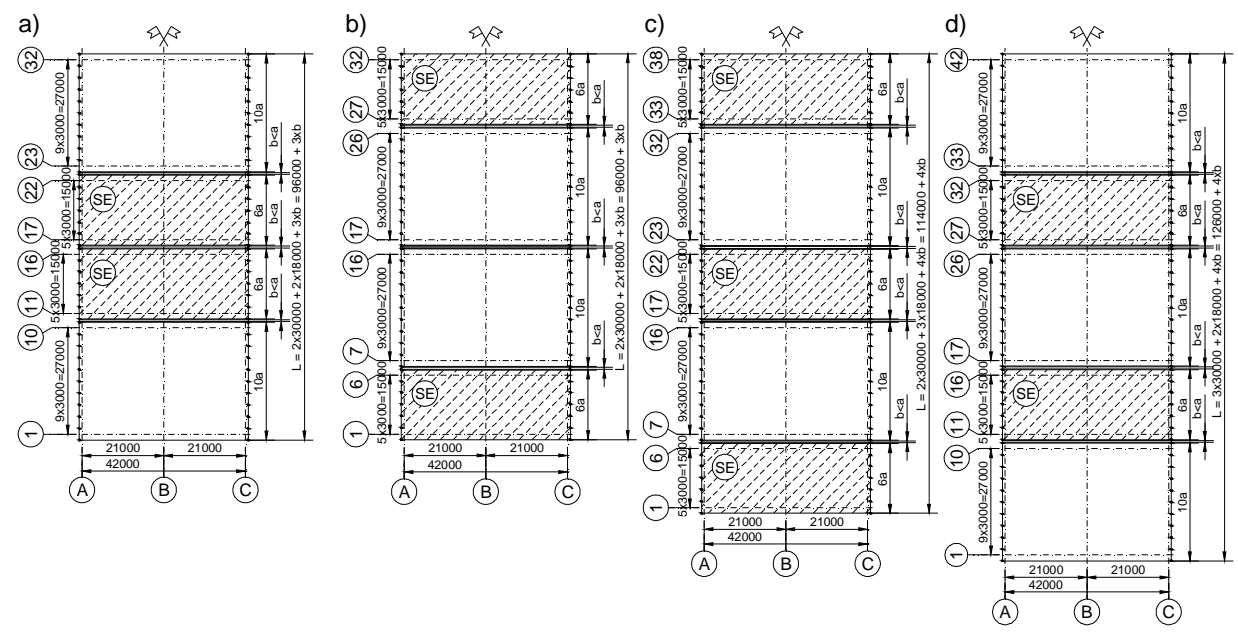

Rys.4. Przykłady rozmieszczenia typowych oraz energoaktywnych (SE) segmentów hali

Fig. 4. Examples of location typical and energy-active (SE) segments 


\section{Oszacowanie nośności i niezawodności minimalnego segmen- tu energoaktywnego}

Minimalne segmenty energoaktywne przekryte strukturą regularną charakteryzują się silnie zredukowanym wpływem temperatury na wytężenie prętów zwłaszcza w przypadku zastosowania przegubów w zwornikach. Pasy górne energoaktywnych segmentów asekurowano zdwojonymi przekrojami prętów skrajnych (rys. 5).

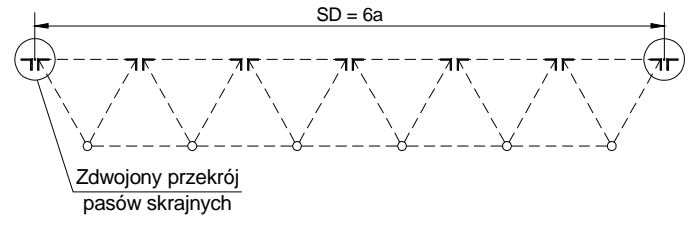

Rys.5. Dodatkowa asekuracja pasów górnych energoaktywnego segmentu dylatacyjnego

Fig. 5. Additional secures of upper chords energy-active segments

Liczbę sprzężonych w KDMZ pasów górnych i w KDMZ pasów dolnych w oszacowaniu nośności i niezawodności pasów, zmniejszono wg wzoru:

$$
n=n_{0}-2
$$

gdzie: $n$ - liczba sprzężonych pasów, $n_{0}$ - zmniejszona liczba elementów sprawczych z uwagi na asekurację.

W przypadku pasów górnych przyjęto do oszacowania $n=n_{0}-2=5$ pasów. W przypadku pasów dolnych przyjęto $n=n_{0}-2=4$ pasy.

Nośność minimalnych geometrycznie niezmiennych segmentów montażowych o szerokości $2 a$ (rys. 2c) oszacowano na obciążenie montażowe metodami konwencjonalnymi. Pręty ściskane pod obciążeniem montażowym, sprawdzono na wyboczenie między węzłami. Dotyczy to prętów rozciąganych w procesie eksploatacji, które zmieniają znak obciążenia w procesie montażu.

Przykład oszacowania nośności i niezawodności w procesie eksploatacji. W przykładzie występuje 9x2 = 18 przedziałów pasów górnych oraz 17 przedziałów pasów dolnych, łącznie $35 \mathrm{KDMZ}$. Każdy z $18 \mathrm{KDMZ}$ pasów górnych zawiera 7 sprzężonych pasów górnych. Każdy z 17 KDMZ pasów dolnych zawiera 6 pasów dolnych. Potencjalna awaryjność $q_{k}$ układu wynosi (2):

$$
q_{k}=35 \cdot q_{1}
$$

gdzie: $q_{1}$ - awaryjność pojedynczego elementu.

Zalecany wskaźnik niezawodności elementów sprawczych klasy RC2 wynosi $t_{2}=3,8$. Niezawodność pojedynczego elementu sprawczego wynosi [10] $p_{1}=0,999927652$, natomiast awaryjność $q_{1}=1-p_{1}=0,000072348$. 
Awaryjność niesprzężonych 35 elementów sprawczych wynosiłaby $q_{k}=35 \cdot q_{1}=35 \cdot 0,000072348=0,00253218$, co daje niezawodność $p_{1}=1-q_{k}=1-0,00253218=0,99746782$ oraz wskaźnik niezawodności rzędu $t_{k}=2,809$ [10]. Zmniejszenie $s_{1}$ nośności układu w stosunku do nośności elementów w przypadku współczynnika zmienności nośności $v_{1}=0,1$, wynosiłoby $0,8622(3)[1]:$

$$
s_{1}=\left(1-t_{2} v_{1}\right) /\left(1-t_{k} v_{1}\right)=\left(1-3,8 v_{1}\right) /\left(1-2,809 v_{1}\right)=0,8622
$$

W segmencie dylatacyjnym występuje asekuracja w postaci równoległego sprzężenia 7 pasów górnych i sprzężenia 6 pasów dolnych. Zwiększenie nośności wskutek sprzężenia w KDMZ pasów górnych oraz KDMZ pasów dolnych $\left(s_{2}\right)$ oszacowano z wzoru (4) [2]:

$$
s_{2}=\left[1-t_{2} v_{1} / n^{0.5}\right] /\left[1-t_{2} v_{1}\right]=\left[1-3,8 v_{1} / 4^{0.5}\right] /\left[1-3,8 v_{1}\right]=1,3065
$$

Nadwyżka nośności wynosi $s_{1} \cdot s_{2}=0,8622 \cdot 1,3065=1,1265$. Nadwyżka rekompensuje [2] wpływ pozostałych połączeń szeregowych.

\section{Podsumowanie, uwagi, wnioski}

Wydzielone segmenty energoaktywne charakteryzują się znaczną powierzchnią dachu, nadającą się do zagospodarowania, w celu pozyskiwania energii cieplnej oraz elektrycznej z promieniowania słonecznego. Wiąże się z tym zwiększenie obciążeń konstrukcji hali wyposażeniem oraz temperaturą. Wydzielenie segmentów energoaktywnych zmniejsza obciążenia termiczne [3] a sprzęganie elementów sprawczych konstrukcji w KDMZ-tach, pozwala na probabilistyczną optymalizację [1] i zwiększanie nośności oraz niezawodności konstrukcji.

W konstrukcjach hal przekrytych strukturami daje się korzystnie wydzielić energoaktywne segmenty dylatacyjne, w których dostateczna liczba elementów sprawczych daje się sprzęgać w KDMZ zwiększając nośność i niezawodność konstrukcji powyżej oczekiwań [9] normowych.

\section{Literatura}

[1] Kowal Z.: On Adjusting the Load Bearing Capacity of Decisive Members to Reliability Classes of Statically Determinate Complex Structures, Archives of Civil Engineering, LIX, 1, 2013, s. $132-142$.

[2] Kowal Z.: Instruments of Probabilistic Optimisation of Load Bearing Capacity and Reliability of Statically Indeterminate Complex Structures, Archives of Civil Engineering, LX, 1, 2014, s. 77 - 90.

[3] Kowal Z., Brzezińska K.: Wpływ temperatury na kinematycznie dopuszczalne mechanizmy zniszczenia energoaktywnych segmentów hali, Praca przyjęta na konferencję ZK2014 - Suchedniów 2014. 
[4] Kowal Z., Piotrowski R.: Energoaktywne segmenty dylatacyjne hal z przekryciem strukturalnym, BiA PL Vol. 12(2) 2013, s. 221 - 228.

[5] Kowal Z., Piotrowski R., Szychowski A.: Przystosowanie hal przekrytych strukturą do pozyskiwania energii z promieniowania słonecznego, ZNPR nr 283, Z. 59 (2/2012/II), s. $431-438$.

[6] Kowal Z., Piotrowski R.: Energoaktywne segmenty dylatacyjne hal przekryte strukturą regularną ze ściągiem, Praca przyjęta na konferencję Lublin - Krynica 2014.

[7] Kowal Z., Piotrowski R., Siedlecka M.: Asekurowany segment energoaktywny hali przekryty strukturą zredukowaną ze ściągiem, Praca przyjęta na konferencję ZK2014 Suchedniów 2014.

[8] Kowal Z., Szychowski A.: Energoaktywne przekrycia łukowe, IiB nr 6/94, s. 251 - 254.

[9] PN-EN 1990:2004, Eurokod: Podstawy projektowania konstrukcji.

[10] Tablice statystyczne rozkładu normalnego.

\title{
ENERGY-ACTIVE SEGMENTS OF HALLS COVERED BY REGULAR ARC STRUCTURE
}

\begin{abstract}
S u m m a r y
The paper presents a concept of hall covered by regular arc structure with significant surface of the roof, which is suitable for deploy a absorbers, to obtain thermal and electricity energy from solar radiation. An additional advantage of arc covering is the increasing insolation of absorbers in winter, what is a result of self-cleaning roof surface. Arrangement and number of absorbers depend on the energy balance of the building. To reduce the thermal influence on structure, typical and energy-active segments were separated in hall. Energy-active segments were composed of geometric invariable assembly segments which enables efficient and secure assembly process. The minimal width of energy-active segment were chosen from condition of minimal thermal influences while maintaining the reliability of the index $t_{2} \geq 3,8$ [9]. It should be adjust the reliability according to the code [9] if it is necessary to reduce the width of the segments. As a result of combination articulated in the ridge achieved the reduction of thermal influence in minimal energy-active segments. Applied the dual cross of upper chords which give the secured antisymmetric movements. Additionaly parallel coupling elements were used in kinematically admissible failure mechanism, what increasing the reliability above recommended for RC2 class [9]. In hall covered by regular arc structure were preferably separated energy-active expansion segments, which a sufficient number of causative elements can be coupled in a KDMZ what increasing capacity and reliability above expectations of code [9].
\end{abstract}

Keywords: energy-active segments of steel halls, metal structures, arc covers, structure reliability

Praca $w$ ramach Projektu pt. „Innowacyjne środki i efektywne metody poprawy bezpieczeństwa $i$ trwałości obiektów budowlanych $i$ infrastruktury transportowej $w$ strategii zrównoważonego rozwoju”, temat 7.4: KONSTRUKCYJNE ROZWIAZZANIA ENERGOAKTYWNYCH PRZEKRYĆ BUDOWLANYCH PRZYSTOSOWANYCH DO POZYSKIWANIA ENERGII CIEPLNEJ. Umowa nr: POIG.01.01.02-10-106.

Przestano do redakcji: 02.12.2014 $r$.

Przyjęto do druku: 22.06.2015 r.

DOI:10.7862/rb.2015.49 